\title{
BIOLOGIA REPRODUTIVA DE CRYPTOSTEGIA MADAGASCARIENSIS \\ BOJER EX DECNE. (PERIPLOCOIDEAE, APOCYNACEAE), ESPÉCIE ORNAMENTAL E EXÓTICA NO BRASIL ${ }^{(1)}$
}

\author{
MILENE FARIA VIEIRA ${ }^{(2,4)}$; MAURO SÉRGIO DE OLIVEIRA LEITE ${ }^{(2,5)}$; \\ JOSÉ ANTONIO SARAIVA GROSSI ${ }^{(3)}$; EVELINE MANTOVANI ALVARENGA ${ }^{(3)}$
}

\begin{abstract}
RESUMO
Foram analisados a fenologia reprodutiva, a biologia floral, o sistema reprodutivo e os polinizadores de Cryptostegia madagascariensis em indivíduos cultivados no campus da Universidade Federal de Viçosa município de Viçosa, Zona da Mata de Minas Gerais. Testaram-se, também, a viabilidade e o vigor de sementes oriundas de frutos abertos naturalmente e a germinação de sementes de frutos ainda fechados, mas com o pericarpo verde-amarelado. C. madagascariensis floresce, principalmente, em novembro e dezembro e os frutos (folículos) podem ser observados durante todo o ano, mas especialmente em janeiro e fevereiro. As flores abrem durante o dia e duram cerca de 24 horas; há protandria, apresentação secundária de pólen e compito intrapistilar, que resulta na produção de folículos gêmeos (dois folículos por flor). É autocompatível, mas a autopolinização espontânea não ocorre devido às características morfológicas. Abelhas devem ser os polinizadores, pois foram os principais insetos observados carregando polinário(s) no aparelho bucal. Em todas as flores analisadas verificou-se que pelo menos um polinário é removido por flor. Entretanto, a baixa frutificação natural $(2,7 \%)$ indica ser esses insetos eficientes na remoção de polinários, mas pouco eficazes na deposição do pólen removido. Os folículos levam cerca de quatro meses para alcançarem o máximo crescimento (média de $6,44 \mathrm{~cm}$ de comprimento, $2,45 \mathrm{~cm}$ de altura e 3,4 cm de largura) e 210 dias para abrirem; a média de sementes por folículo é 96,5. As condições ideais para avaliar a qualidade de sementes, de folículos abertos naturalmente, são temperatura de $30^{\circ} \mathrm{C}$ constante, sem suplementação de luz, e contagem de germinação aos sete dias. Sementes de folículos ainda fechados apresentaram 93\% de germinação, nessas condições.
\end{abstract}

Palavras-chave: biologia floral, sistema reprodutivo, polinização, abelhas, germinação de sementes.

\begin{abstract}
REPRODUCTIVE BIOLOGY OF CRYPTOSTEGIA MADAGASCARIENSIS BOJER EX DECNE. (PERIPLOCOIDEAE, APOCYNACEAE), AN ORNAMENTAL AND EXOTIC SPECIES OF BRAZIL

Reproductive phenology, floral biology, breeding system and pollinators were analyzed on Cryptostegia madagascariensis individuals cultivated at Federal University of Viçosa campus, municipality of Viçosa, Zona da Mata of Minas Gerais State. In addition, seed viability and vigour from naturally opened fruits were tested. Seed germination from yellow-green pericarp closed fruits was also tested. Flowering of C. madagascariensis occurs mainly in November and December. Fruits (follicles) are exhibited during all year, but more frequently in January and February. Flowers open during the day and last about 24 hours. They exhibit protandry, secondary pollen presentation and intragynoecial compitum,
\end{abstract}

${ }^{1}$ ) Recebido para publicação em 24 de julho de 2003 e aceito em 4 de maio de 2004.

$\left(^{2}\right)$ Departamento de Biologia Vegetal, Universidade Federal de Viçosa, 36570-000, Viçosa (MG). E-mail: mfvieira@ufv.br

$\left({ }^{3}\right)$ Departamento de Fitotecnia, Universidade Federal de Viçosa.

$\left({ }^{4}\right)$ Com Bolsa de Pesquisa do CNPq.

$\left({ }^{5}\right)$ Bolsista PIBIC/CNPq. 
which results in the production of twin follicles (two follicles per flower). It is self-compatible, but spontaneous self-pollination does not occur due to morphological characteristics. Bees should be the main pollinators, as they exhibited the pollinarium attached to their mouthparts. At least one pollinarium was removed per flower. However, the low natural fructification $(2.7 \%)$ rate indicates that these insects are efficient for pollinaria removal, but less efficient for deposition of collected pollen. The follicles take four months to reach the maximum size (average of $6.44 \mathrm{~cm}$ length, $2.45 \mathrm{~cm}$ height and $3.4 \mathrm{~cm}$ width), and 210 days for opening. Each follicle averaged 96.5 seeds. The ideal conditions for seed quality evaluation, from naturally opened follicles, were $30^{\circ} \mathrm{C}$ constant temperature and no supplementary light, and counting occurred at the $7^{\text {th }}$ days. Seeds from closed follicles showed $93 \%$ germination under those conditions.

Key words: floral biology, breeding system, pollination, bees, seed germination.

\section{INTRODUÇÃO}

Espécies vegetais têm sido introduzidas no território brasileiro há séculos, sendo usadas, por exemplo, como alimento ou na ornamentação, e, muitas delas, propagadas assexuadamente, por meio de estacas, bulbos, rizomas ou tubérculos. A ausência de agentes polinizadores, que permanecem restritos ao local de origem da planta, é uma das causas da não-produção de sementes. Entretanto, espécies com flores que produzem recursos abundantes (p.ex. pólen e néctar) podem atrair animais antófilos da região onde foram introduzidas e, dependendo do comportamento e da constância de visitas, esses animais podem atuar como polinizadores, possibilitando a reprodução sexuada.

De acordo com ENDRESS e BRUYNS (2000), a família Apocynaceae s.l. compreende cinco subfamílias: Rauvolfioideae, Apocynoideae (Apocynaceae s.s.), Periplocoideae, Secamonoideae e Asclepiadoideae (Asclepiadaceae). Periplocoideae tem distribuição restrita ao Velho Mundo, principalmente a África, incluindo Madagascar, e Ásia (Verhoeven e Venter, 1998), e possui 40 gêneros, dentre eles, Cryptostegia R. Br. (ENDRESS e BRUYNS, 2000). Esse gênero compreende duas espécies, $C$. grandiflora Roxb. ex R. Br. e C. madagascariensis Bojer ex Decne., endêmicas em Madagascar (MAROHASY e ForSTER, 1991; KLACKENBERG, 2001), porém amplamente naturalizadas em regiões tropicais do mundo. Na Austrália, C. grandiflora é polinizada por insetos e propaga-se por meio de sementes (Tomley, 1995). Grice (1996) ressaltou que, em um episódio reprodutivo, essa espécie pode dispersar 8.000 sementes e mais de $90 \%$ delas germinaram dentro de 10 dias, em condições favoráveis, no norte da Austrália. No Brasil, LORENZI e Souza (1999) citaram o cultivo, como ornamental, de C. grandiflora e mencionaram que essa planta tem sido propagada por meio de sementes e, com dificuldade, por estacas.

No campus da Universidade Federal de Viçosa, localizado no município de Viçosa $\left(20^{\circ} 45^{\prime} \mathrm{S}\right.$ e $\left.42^{\circ} 51^{\prime} \mathrm{W}\right)$, Zona da Mata do Estado de Minas Gerais, alguns indivíduos de C. madagascariensis são cultivados como ornamentais, nos quais se observa, comumente, a formação de frutos, indicando a participação de agentes polinizadores, uma vez que suas flores não se autopolinizam, por apresentarem hercogamia.

Os objetivos do presente estudo foram analisar a fenologia reprodutiva, a biologia floral, o sistema reprodutivo e os polinizadores dessa espécie; foram testados, também, a viabilidade e o vigor de sementes, visando à produção de mudas.

\section{MATERIAL E MÉTODOS}

O trabalho foi realizado de agosto de 2001 a dezembro de 2002, com três indivíduos de Cryptostegia madagascariensis, cultivados no campus da UFV e distantes entre si cerca de 500 metros: o primeiro localizado no Horto Botânico, o segundo, no prédio da Biologia e o terceiro, na Floricultura. No município de Viçosa, a altitude varia de 600 a 850 metros e o clima caracteriza-se por apresentar temperatura média anual de $19{ }^{\circ} \mathrm{C}$, precipitação anual de 1.300 a 1.400 $\mathrm{mm}$, ocorrendo maior precipitação no período de outubro a março (Vieira e Grabalos, 2003). Material testemunho foi incluído no Herbário do Departamento de Biologia Vegetal da Universidade Federal de Viçosa (VIC no. 26.048, 26.049 e 26.050).

Os indivíduos de C. madagascariensis são arbustivos, com cerca de 2,0 a 3,0 m de altura, latescentes. Apesar de arbustiva, essa espécie desenvolve ramos trepadores, que, se não podados, podem alcançar alturas consideráveis, usando como suporte, por exemplo, outras plantas. Suas inflorescências são cimas dicasiais (Figura 1A) e as flores apresentam cinco sépalas verdes, cinco pétalas róseas, cinco elementos de corona (Figura 1B) corolinos (Liede e Kunze, 1993), cinco estames epipétalos e alternos às pétalas, dois ovários, dois estiletes e a cabeça dos estiletes (Figura 1B, C); anteras e cabeça dos estiletes unem-se para formar o ginostégio (ENDRESS e BRUYNS, 2000). 
Na cabeça dos estiletes são formados cinco transladores rudimentares, cada um posicionado entre duas anteras adjacentes; sobre os transladores são depositados os grãos de pólen (Figura 1C) de duas anteras adjacentes (VerHoEven e Venter, 1998), formando os polinários (total de cinco por flor, Figura
1C), cada um sendo transportado pelos polinizadores (Vieira e Shepherd, 2002). Os frutos são do tipo folículo (Figura 1D), ou seja, seco, deiscente, com uma deiscência longitudinal, e as sementes, comosas (Figura 1E; BARroso et al., 1999), anemocóricas (PIJL, 1982).

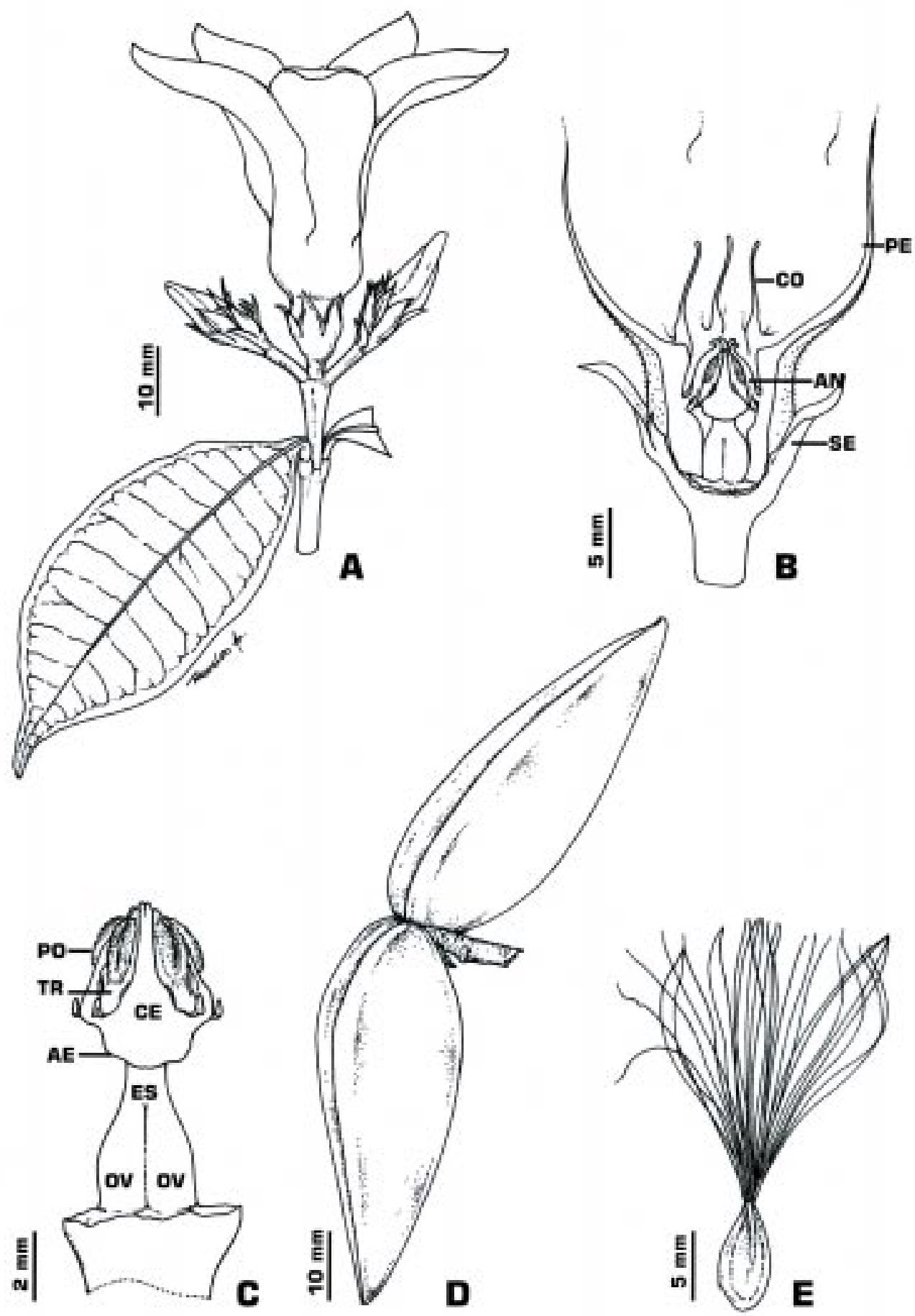

Figura 1. Cryptostegia madagascariensis. A: Inflorescência em dicásio, com a flor central aberta; B: Flor em corte longitudinal (parte da corola foi removida): SE - sépala, PE - pétala, CO - elemento de corona, AN - antera; C: Gineceu e polinários (cada um constituído de translador e grãos de pólen depositados sobre ele): PO - pólen, TR - translador, OV - ovário, ES - estiletes, AE área estigmatífera, CE - cabeça dos estiletes; D: Folículos gêmeos (dois frutos de uma flor); E: Semente comosa. 
A fenologia reprodutiva foi registrada nos três indivíduos, nos quais foram observadas, quinzenalmente e durante o período de estudo, a presença ou ausência de botões florais e/ou flores abertas e de frutos imaturos e maduros. Para os estudos sobre a biologia floral foram registrados o horário de abertura das flores, de deiscência das anteras e a duração das flores.

Para os estudos sobre o sistema reprodutivo foram realizados os seguintes tratamentos, com base no método de KeARNS e INOUYE (1993): 1) polinização cruzada - as flores foram ensacadas na pré-antese e, quando abertas, receberam pólen de outro indivíduo; 2) autopolinização manual - as flores foram ensacadas na pré-antese e, quando abertas, foram polinizadas com o próprio pólen; e 3) controle - as flores foram apenas etiquetadas. Nesses tratamentos, utilizou-se somente uma flor por inflorescência, pois nos indivíduos estudados observou-se, a priori, apenas uma flor por inflorescência resultando em fruto (em 91,2\% dos frutos observados; $N=34$ ). Os sacos utilizados foram confeccionados com tecido do tipo organza.

Outras flores também foram polinizadas manualmente (autopolinização e polinização cruzada), com os grãos de pólen de um polinário depositados em uma porção apenas da região estigmatífera ( $c f$. ENDRESS e BRUYNS, 2000), e analisadas após 24 e 48 horas, em microscopia de fluorescência, utilizando-se a técnica de MARTIN (1959) para verificar o percurso e crescimento dos tubos polínicos.

Foi acompanhado o desenvolvimento de frutos, nos indivíduos estudados, medindo-os (comprimento, maior largura e maior altura) semanalmente e caracterizando-os morfologicamente, conforme BebaWi e McKenZIE (1999).

Para verificar a viabilidade, o vigor das sementes e as melhores condições para sua germinação, os frutos foram ensacados e, depois de abertos (naturalmente), as sementes foram coletadas, contadas e preparadas. Para o teste de germinação, as sementes foram desinfetadas com hipoclorito de sódio a $1 \%$, durante cinco minutos e colocadas para germinar em caixas plásticas (gerbox), sobre três folhas de papel-filtro umedecido com água destilada, na proporção de 2,5 vezes o peso do papel. Foram, então, levadas para germinadores regulados em três diferentes condições de temperaturas: $25^{\circ} \mathrm{C}$ e $30^{\circ} \mathrm{C}$ constantes e 20 a $30{ }^{\circ} \mathrm{C}$ alternados $\left(16\right.$ horas a $30^{\circ} \mathrm{C}$ e 8 horas a $20^{\circ} \mathrm{C}$ ), simulando as condições do dia e da noite, onde permaneceram por 15 dias. Para cada condição de temperatura, as sementes foram submetidas a três condições de luminosidade: luz ambiente, luz suplementar e sem luz (gerbox coberto com papel de alumínio), totalizando nove tratamentos, utilizando repetições de 25 sementes. O experimento foi organizado em esquema fatorial $3 \times 3$, no delineamento inteiramente casualizado, com seis repetições. As avaliações foram feitas aos cinco, sete e 15 dias e contados os números de plântulas normais, caracterizadas por possuírem radícula, hipocótilo e cotilédones bem desenvolvidos e formados, e de plântulas anormais deformadas, identificadas pela falta ou má-formação de radícula ou parte aérea. O vigor das sementes foi avaliado na primeira contagem do teste de germinação, visando ao registro da porcentagem de plântulas normais e do comprimento $(\mathrm{cm})$ de radícula dessas plântulas. A data para efetuar a primeira contagem foi preliminarmente definida pelo desenvolvimento das plântulas nas três avaliações, ou seja, aos cinco, sete e 15 dias, tendo sido estipulado o $7^{0}$ dia como o ideal, neste trabalho.

Sementes obtidas a partir de frutos ainda fechados e com coloração verde-amarelada também foram testadas quanto à viabilidade, utilizando-se metodologia idêntica à do teste de germinação de sementes de frutos abertos, em condições que melhor revelaram a viabilidade, conforme os mesmos indicadores.

Os visitantes florais foram observados durante o pico de floração, nos três indivíduos estudados. Em cada indivíduo, no período das $8 \mathrm{~h}$ às $11 \mathrm{~h}$, em dias nãoconsecutivos, foram coletados todos os insetos que visitavam as flores, capturados diretamente em câmara mortífera e imediatamente analisados para verificar a presença ou ausência de polinários nos seus corpos. Posteriormente, foram montados em alfinetes entomológicos, etiquetados e depositados na coleção de abelhas do Museu de Entomologia do Departamento de Biologia Animal, da Universidade Federal de Viçosa e da Universidade Federal de Minas Gerais.

A atividade dos visitantes foi quantificada pela remoção de polinários, em flores senescentes. Essas flores foram coletadas durante o pico de floração, conservadas em álcool $70 \%$ e, posteriormente, analisadas sob estereomicroscópio para registrar o número de polinários removidos (VIEIRA e SHEPHERD, 2002).

\section{RESULTADOS E DISCUSSÃO}

Os indivíduos estudados apresentaram um pico de floração em novembro e dezembro; em dois deles a floração ocorreu de novembro a julho, e nos três últimos meses apresentavam apenas uma ou duas flores abertas por dia; o terceiro indivíduo apresentou flores e/ou botões florais ao longo do ano todo. 
A floração sincronizada, especialmente nos meses de pico, pode ser resultado da influência climática (elevação da temperatura e estação chuvosa) sobre essa fenofase. TOMLEy (1995) verificou que $C$. grandiflora, na Austrália, pode florescer durante todo o ano se a temperatura e água não forem os fatores limitantes; segundo esse mesmo autor, no Haiti, os indivíduos estudados florescem sempre na mesma época, anualmente, e a produção de frutos está relacionada com a distribuição das chuvas, com a maioria produzidos dois meses após os picos de pluviosidade, tal como observado no presente estudo.

O processo de abertura da flor é lento, levando cerca de 12 horas, e caracterizado pelo desenrolar das pétalas, a partir da prefloração espiralada. A abertura das flores pode ocorrer pela manhã ou ao entardecer; em ambos os casos, as flores permanecem abertas durante a noite e duram cerca de 24 horas, duração semelhante à registrada em C. grandiflora por TOMLEy (1995).

A abertura das anteras ocorre em botões na pré-antese, ocasião em que os grãos de pólen são depositados sobre os transladores, caracterizando a protandria e a apresentação secundária de pólen (YEO, 1994). Essas duas características são comumente observadas nas espécies de Apocynaceae s.s. (Rauvolfioideae e Apocynoideae, Yeo, 1994; Lopes e MACHADO, 1999), mas são inéditas nas Periplocoideae. Nessa subfamília, segundo Verhoeven e Venter (1998), os grãos de pólen são depositados nos transladores na ocasião da abertura da flor, diferindo do observado no presente estudo. Após 24 horas, ocorre a abscisão das pétalas, juntamente com os estames e a cabeça dos estiletes, restando somente sépalas, ovários e estiletes.

C. madagascariensis é autocompatível, considerando os resultados obtidos após as autopolinizações (Tabela 1). Observou-se aborto de frutos nos três tratamentos (Tabela 1), em diferentes estádios de desenvolvimento. Autocompatibilidade e aborto de frutos são características já registradas em espécies de Asclepiadaceae (WyAtT e Broyles, 1994; Vieira e Shepherd, 1999; Vieira e Grabalos, 2003). A frutificação (frutos em desenvolvimento), após a polinização aberta $(9,3 \%$, Tabela 1$)$, se comparada com a obtida após as polinizações manuais $(60 \%$ a $74 \%$, Tabela 1), indica baixo nível de polinização natural das flores de C. madagascariensis. Resultados semelhantes foram observados em espécies nativas de Oxypetalum, também na região de Viçosa (VIEIRA e SHEPHERD, 1999; Vieira e Grabalos, 2003).

O baixo nível de polinização natural, resultando em baixa frutificação, pode estar relacionado ao complexo mecanismo de polinização de espécies de Asclepiadaceae (Vieira e Grabalos, 2003), que parece ser compensado pela produção de muitas sementes por fruto. A área estigmatífera de $C$. madasgascariensis restringe-se à região basilar da cabeça dos estiletes (Figura 1C), tal como mencionado por ENDRESS e BRUYNS (2000), e os grãos de pólen, quando depositados sobre os transladores, não alcançam essa região (Figura 1C), caracterizando a hercogamia.

Na microscopia de fluorescência observou-se que, após autopolinização e polinização cruzada, os grãos de pólen germinam e os tubos polínicos crescem nos dois estiletes e ovários, mostrando que, cada flor, pode produzir dois frutos (folículos gêmeos, Figura 1D). De fato, $56,4 \%$ dos frutos resultantes das polinizações manuais (Tabela 1) foram de folículos gêmeos, embora o aborto de um desses folículos seja comum. Esses resultados demonstram a presença de compito (sensu CARR e CARR, 1961) intrapistilar, raramente observado em espécies de Asclepiadaceae (KunZe, 1991), porém comumente citado em espécies de Apocynaceae s.s. (CARr e CARr, 1961; WAlKer, 1978). Os tubos polínicos alcançaram os óvulos 48 horas após os tratamentos.

Tabela 1. Polinizações naturais e manuais em flores de Cryptostegia madagascariensis, de indivíduos cultivados em Viçosa, Minas Gerais

\begin{tabular}{|c|c|c|c|c|c|}
\hline Tratamentos & Indivíduos & Inflorescência & Flores & $\begin{array}{c}\text { Frutos }{ }^{(1)} \text { em } \\
\text { desenvolvimento }\end{array}$ & $\begin{array}{l}\text { Frutos }{ }^{(1)} \text { que } \\
\text { amadureceram }\end{array}$ \\
\hline & \multicolumn{3}{|c|}{$\mathrm{n} \cdot{ }^{\mathrm{o}}$} & \multicolumn{2}{|c|}{ n. $.^{\circ} / \%$} \\
\hline Polinização cruzada & 2 & 19 & 19 & $14 / 73,7$ & $2^{(2)} / 10,5$ \\
\hline Autopolinização & 2 & 20 & 20 & $12 / 60,0$ & $3^{(3)} / 15,0$ \\
\hline Controle & 2 & 75 & 75 & $07 / 09,3$ & $2^{(4)} / 02,7$ \\
\hline
\end{tabular}

( $\left.{ }^{1}\right)$ Folículo único (um folículo por flor) ou folículos gêmeos (dois folículos por flor).; $\left({ }^{2}\right)$ Doze frutos abortaram.; $\left({ }^{3}\right)$ Nove frutos abortaram.; $\left({ }^{4}\right)$ Seis frutos abortaram. 
Em Viçosa, os frutos (um folículo ou folículos gêmeos) podem ser observados durante todo o ano, em diferentes estádios de desenvolvimento, especialmente porque o período de floração é longo e pelo lento desenvolvimento dos frutos, ou seja, cerca de sete meses (210 dias) até a abertura e liberação das sementes. Entretanto, observou-se a maioria dos frutos após o pico de floração, em janeiro e fevereiro. O folículo leva cerca de quatro meses para atingir seu crescimento máximo de, em média, $6,44 \mathrm{~cm}$ de comprimento, $2,45 \mathrm{~cm}$ de altura e $3,40 \mathrm{~cm}$ de largura $(N=15)$. Nos três meses seguintes, a tendência é a perda da latescência e da coloração verde, substituída por verde-amarelada e, por último, tornando-se marrom.

Nessa época, encontra-se totalmente seco, com muitas rugas longitudinais, e pronto para abrir. Cada folículo produz, em média, $96,5 \pm 7,8$ sementes $(N=10)$. Em C. grandiflora, os folículos também apresentam desenvolvimento lento (173 dias), mas são maiores, medindo, na maturidade, cerca de $12,5 \mathrm{~cm}$ de comprimento e produzem mais sementes, em média 668 por fruto, segundo TOMLEY (1995).

O número de sementes por fruto, dessa espécie, é controverso: GRICE (1996) registrou $279 \pm 11(N=58)$ e J. Vitelli, citado por Tomley (1995), de 340-380 sementes. As diferenças podem estar relacionadas ao que os autores consideraram como fruto: ou cada um dos folículos produzidos por uma flor, como considerado no presente estudo, ou se os dois folículos por flor, que deve explicar o elevado número de sementes registrado por TOMLEy (1995).

$\mathrm{O}$ fruto de C. grandiflora também apresenta alterações de cor durante a maturação (verde e marrom) (Bebawi e McKenzie, 1999). Esses autores consideraram, além da cor, a "lenhosidade" e a presença de fibras no pericarpo como fatores para identificação de sua maturidade, características que não foram analisadas no presente estudo.

Os resultados de germinação das sementes estão apresentados nas tabelas 2 e 3 e os resultados de vigor, nas tabelas 4 e 5 . A análise de variância mostrou que a interação temperatura $x$ luminosidade foi significativa para todos os parâmetros avaliados. Para a porcentagem de plântulas normais, não houve diferença estatística entre as temperaturas testadas em condições de luz ambiente e suplementar (Duncan, $\mathrm{p}<0,05$ ) (Tabela 2). Na ausência de luz, entretanto, a germinação das sementes a $30^{\circ} \mathrm{C}$ caiu drasticamente e manteve-se máxima nas condições de $25^{\circ} \mathrm{C}$ e de 20 a $30^{\circ} \mathrm{C}$ (Tabela 2$)$.

Tabela 2. Resultados médios de germinação, sob diferentes condições de temperatura e luminosidade, de sementes de indivíduos de Cryptostegia madagascariensis cultivados em Viçosa, Minas Gerais

\begin{tabular}{|c|c|c|c|}
\hline \multirow{2}{*}{ Luz } & \multicolumn{3}{|c|}{ Temperatura } \\
\hline & $25^{\circ} \mathrm{C}$ & $30^{\circ} \mathrm{C}$ & $20-30^{\circ} \mathrm{C}$ \\
\hline Ambiente & $80,00 \quad \mathrm{~A}$ a b & $90,00 \mathrm{~A} \mathrm{a}$ & $82,00 \mathrm{~A} \mathrm{a}$ \\
\hline Suplementar & $74,00 \quad \mathrm{~A} \mathrm{~b}$ & 57,33 A b & $76,00 \mathrm{~A} \mathrm{a}$ \\
\hline Escuro & $85,33 \quad \mathrm{~A}$ a & 10,67 В с & $81,33 \mathrm{~A} \mathrm{a}$ \\
\hline
\end{tabular}

Médias seguidas pela mesma letra maiúscula, nas linhas, e minúscula, nas colunas, não diferem estatisticamente entre si, pelo teste de Duncan a 5\% de probabilidade.

O número de plântulas deformadas a $30{ }^{\circ} \mathrm{C}$ atingiu $56 \%$ na ausência de luz e $0 \%$ em luz ambiente (Tabela 3). Quando se colocaram as sementes de $C$. madagascariensis para germinar no escuro, em condições de temperaturas de $25^{\circ} \mathrm{C}$ e de 20 a $30^{\circ} \mathrm{C}$, foram obtidas mais de $80 \%$ de plântulas normais (Tabela 2), porém bastante estioladas.

Segundo Sem (1968) apud Tomley (1995), sementes de C. grandiflora, ao contrário das de C. madagascariensis, germinam melhor no escuro, sendo mais rápido em temperaturas que variam de 25 a 30
${ }^{\circ} \mathrm{C}$, embora sob temperaturas mais baixas $\left(<15{ }^{\circ} \mathrm{C}\right)$ ocorra alguma germinação com iluminação contínua.

Grice (1996), em trabalho com sementes de $C$. grandiflora de seis meses de idade, em temperaturas de $15,20,25,30,35$ e $40^{\circ} \mathrm{C}$, obteve germinação acima de $80 \%$ nas temperaturas de 20,25 , e $30{ }^{\circ} \mathrm{C}$, semelhantemente ao observado no presente estudo. Entretanto, esse autor não mencionou as condições de luminosidade empregadas e o critério de avaliação das sementes germinadas foi apenas o de emergência de radículas. 
Tabela 3. Resultados médios do número de plântulas anormais deformadas no teste de germinação sob diferentes condições de temperatura e luminosidade, de sementes de indivíduos de Cryptostegia madagascariensis cultivados em Viçosa, Minas Gerais

\begin{tabular}{|c|c|c|c|}
\hline \multirow{2}{*}{ Luz } & \multicolumn{3}{|c|}{ Temperatura } \\
\hline & $25^{\circ} \mathrm{C}$ & $30^{\circ} \mathrm{C}$ & $20-30^{\circ} \mathrm{C}$ \\
\hline & & $\%$ & 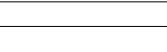 \\
\hline Ambiente & $0,67 \mathrm{~B} \mathrm{~b}$ & $0,00 \mathrm{~B} \mathrm{~b}$ & $5,33 \mathrm{~A} \mathrm{a} \mathrm{b}$ \\
\hline Suplementar & $8,67 \mathrm{~A} \mathrm{a}$ & $2,67 \mathrm{~A} \mathrm{~b}$ & $7,33 \mathrm{~A}$ a \\
\hline Escuro & $10,00 \mathrm{~B} \mathrm{a}$ & $56,00 \mathrm{~A} \mathrm{a}$ & $2,00 \mathrm{~B} \mathrm{~b}$ \\
\hline
\end{tabular}

Médias seguidas pela mesma letra maiúscula, nas linhas, e minúscula, nas colunas, não diferem estatisticamente entre si, pelo teste de Duncan a $5 \%$ de probabilidade.

O vigor das sementes também foi máximo sob condição de luz ambiente e temperatura de $30{ }^{\circ} \mathrm{C}$ (Tabelas 4 e 5).

Sementes de frutos ainda fechados apresentaram, em média, 93\% de germinação, concluindo que os frutos com pericarpo verdeamarelado contêm sementes que, provavelmente, podem ser utilizadas para propagação, reduzindo o tempo de espera pela sua maturação. Resultado semelhante foi obtido por BEBAwI e MCKENZIE (1999) em C. grandiflora. Nos três indivíduos de $C$. madagascariensis foram coletadas, principalmente, abelhas visitando as flores e carregando polinário no aparelho bucal (Tabela 6), parecendo mostrar que podem atuar como polinizadores (OlLERTON e LIEDE, 1997). Esses dados diferem dos de Walther (1994) apud Ollerton e Liede (1997), que constatou mariposas noturnas como polinizadores de Cryptostegia.

Tabela 4. Resultados médios do comprimento da radícula de plântulas normais, no teste de germinação sob diferentes condições de temperatura e luminosidade, de sementes de indivíduos de Cryptostegia madagascariensis cultivados em Viçosa, Minas Gerais

\begin{tabular}{lrrrr}
\hline & \multicolumn{4}{c}{ Temperatura } \\
\cline { 2 - 4 } & \multicolumn{2}{c}{$25^{\circ} \mathrm{C}$} & $30^{\circ} \mathrm{C}$ & $20-30^{\circ} \mathrm{C}$ \\
\cline { 2 - 4 } & $3,23 \mathrm{~B} \mathrm{a}$ & $\mathrm{cm}$ & \\
Ambiente & 3,55 A a & 4,21 A a & $2,75 \quad \mathrm{C} \mathrm{a}$ \\
Suplementar & - & 1,13 C b & B b \\
Escuro & & - & - \\
\hline
\end{tabular}

Médias seguidas pela mesma letra maiúscula, nas linhas, e minúscula, nas colunas, não diferem estatisticamente entre si, pelo teste de Duncan a $5 \%$ de probabilidade.

Tabela 5. Resultados médios (\%) do número de plântulas normais obtidas na primeira contagem do teste de germinação aos sete dias, sob diferentes condições de temperatura e luminosidade, de sementes de Cryptostegia madagascariensis, em Viçosa, Minas Gerais

\begin{tabular}{|c|c|c|c|}
\hline \multirow{2}{*}{ Luz } & \multicolumn{3}{|c|}{ Temperatura } \\
\hline & $25^{\circ} \mathrm{C}$ & $30^{\circ} \mathrm{C}$ & $20-30^{\circ} \mathrm{C}$ \\
\hline Ambiente & $74,67 \quad \mathrm{~A} \mathrm{~B} \mathrm{a}$ & $86,67 \quad \mathrm{~A} \mathrm{a}$ & $62,00 \quad \mathrm{~B}$ a \\
\hline Suplementar & $71,33 \quad \mathrm{~A} a$ & $8,00 \quad \mathrm{C} \mathrm{b}$ & $36,67 \quad \mathrm{~B} \mathrm{~b}$ \\
\hline Escuro & - & - & - \\
\hline
\end{tabular}

Médias seguidas pela mesma letra maiúscula, nas linhas, e minúscula, nas colunas, não diferem estatisticamente entre si, pelo teste de Duncan a $5 \%$ de probabilidade. 
Além das abelhas, foram coletadas duas espécies de borboletas (Tabela 6), ambas da família Hesperiidae, também com polinário no aparelho bucal; esses lepidópteros, entretanto, são diurnos. No presente estudo, não foram realizadas observações à noite, embora as flores permaneçam abertas nesse período, possibilitando que sejam visitadas por insetos noturnos; há necessidade de comprovar essa suposição.

O comportamento de visita dos insetos que carregavam polinário foi semelhante. Pousavam nos lobos da corola ou diretamente no tubo da corola (face ventral) e caminhavam até próximo aos estames. Por entre duas anteras adjacentes e a corola, introduziam o aparelho bucal no interior do tubo floral, buscando, provavelmente, néctar. Desse modo, o inseto contatava o polinário, localizado entre anteras adjacentes e opostamente à corola, que aderia ao dorso do seu aparelho bucal (cada polinário possui um disco adesivo; Verhoeven e Venter, 1998). Cada inseto carregava um polinário, raramente dois, e visitava várias flores de um mesmo indivíduo, favorecendo a autopolinização ou a geitonogamia (transferência de pólen entre flores de um mesmo indivíduo; RICHARDS, 1986).
Outro fator que deve favorecer essas estratégias reprodutivas é o predomínio de uma espécie de abelha somente em um dado indivíduo de C. madagascariensis (Tabela 6). Esse predomínio, entretanto, deve ser analisado com cuidado, pois pode refletir as condições encontradas durante o período deste estudo, pois a flora antófila pode variar de um ano para outro, como observado por FishbeIn e VenAbLE (1996).

Ollerton e Liede (1997) ressaltaram que apenas 3,3\% das espécies (total de cerca de 180 espécies) de Periploceae, tribo à qual pertence Cryptostegia, apresentam alguma informação sobre polinizadores/visitantes florais; nessa tribo, somente insetos das ordens Lepidoptera (por exemplo, em Cryptostegia) e Diptera foram registrados como polinizadores. Esses autores também observaram que espécies cultivadas fora da sua área de ocorrência natural têm sido visitadas pela mesma ordem de insetos do local de origem. Essa afirmativa não se confirmou para os indivíduos cultivados de $C$. madagascariensis, na região de Viçosa, pois as abelhas (Hymenoptera) foram os visitantes florais mais freqüentes.

Tabela 6. Visitantes florais coletados em três indivíduos de Cryptostegia madagascariensis, cultivados em Viçosa, Minas Gerais

\begin{tabular}{lccc}
\hline \multirow{2}{*}{ Espécies } & \multicolumn{3}{c}{ Indivíduos coletados } \\
\cline { 2 - 4 } & Horto Botânico & Biologia & Floricultura \\
\hline
\end{tabular}

Hymenoptera (abelhas)

\begin{tabular}{|c|c|c|c|}
\hline Apis mellifera ${ }^{(1)}$ & 1 & 14 & 1 \\
\hline Trigona spinipes & 3 & 0 & 0 \\
\hline Thygater (Thygater) analis ${ }^{(1)}$ & 9 & 2 & 4 \\
\hline Monoeca sp. ${ }^{(1)}$ & 0 & 0 & 7 \\
\hline Euglossa (Euglossa) townsendi ${ }^{(1)}$ & 0 & 1 & 1 \\
\hline Peponapis (Colocynthophila) fervens & 1 & 1 & 0 \\
\hline Bombus atratus & 0 & 1 & 0 \\
\hline Total & 14 & 19 & 13 \\
\hline \multicolumn{4}{|l|}{ Lepidoptera (borboletas) } \\
\hline morfo-espécie $1{ }^{(1)}$ & 1 & 0 & 2 \\
\hline morfo-espécie $2^{(1)}$ & 0 & 1 & 0 \\
\hline Total & 1 & 1 & 2 \\
\hline
\end{tabular}

$\left({ }^{1}\right)$ Insetos com polinário(s) no aparelho bucal. 
Tabela 7. Remoção de polinários em flores de Cryptostegia madagascariensis, de indivíduos cultivados em Viçosa, Minas Gerais

\begin{tabular}{|c|c|c|c|c|c|c|c|c|}
\hline \multirow[t]{2}{*}{ Local } & \multirow{2}{*}{$\begin{array}{c}\text { Flores } \\
\text { examinadas } \\
\text { n. }{ }^{\circ}\end{array}$} & \multicolumn{6}{|c|}{$\begin{array}{c}\text { Polinários removidos } \\
\text { (n. }{ }^{\circ} \text { de flores } / \% \text { de flores) }\end{array}$} & \multirow{2}{*}{$\begin{array}{l}\text { Polinários } \\
\text { removidos por flor }\end{array}$} \\
\hline & & 0 & 1 & 2 & 3 & 4 & 5 & \\
\hline Horto Botânico & 65 & 0 & $10 / 15,3$ & $21 / 32,30$ & $17 / 26,15$ & $8 / 12,30$ & $9 / 13,84$ & 2,8 \\
\hline Biologia & 55 & 0 & $3 / 5,45$ & $9 / 16,36$ & $21 / 38,18$ & $7 / 12,72$ & $15 / 27,27$ & 3,4 \\
\hline Floricultura & 41 & 0 & $1 / 2,44$ & $2 / 4,88$ & $12 / 29,27$ & $16 / 39,02$ & $10 / 24,39$ & 3,8 \\
\hline Total & 161 & 0 & $14 / 8,7$ & $32 / 19,9$ & $50 / 31,0$ & $31 / 19,3$ & $34 / 21,1$ & 3,2 \\
\hline
\end{tabular}

Nas flores analisadas, para verificar as atividades dos visitantes florais (insetos, Tabela 6), foi registrado pelo menos um polinário removido em todas elas e 3,2 polinários removidos por flor (Tabela 7). Esse último resultado revela que os insetos são eficientes na remoção de polinários, se comparado com os resultados obtidos para a maioria das espécies de Asclepiadaceae analisada sob esse aspecto (VIEIRA e Shepherd, 2002). Entretanto, o resultado do tratamento-controle (Tabela 1) demonstrou que as flores de C. madagascariensis apresentam baixo nível de polinização, ou seja, os insetos não parecem ser eficientes na deposição do pólen removido. Alta remoção de polinários e baixa deposição de grãos de pólen removidos também foram registrados em flores de Oxypetalum banksii Roem. \& Schult. subsp. banksii e O. subriparium Malme, na região de Viçosa (VIEIRA e SHEPHERD, 2002).

\section{CONCLUSÕES}

1. Cryptostegia madagascariensis floresce, principalmente, durante a estação chuvosa, em novembro e dezembro, e os frutos podem ser observados ao longo do ano, especialmente, em janeiro e fevereiro.

2. As flores abrem durante o dia e duram cerca de 24 horas; há protandria, apresentação secundária de pólen e compito intrapistilar; essa última característica resulta na produção de dois folículos por flor (folículos gêmeos).

3. É autocompatível, mas autopolinização espontânea não ocorre devido às características morfológicas.

4. As flores devem ser polinizadas principalmente por abelhas, que carregam polinário(s) no aparelho bucal.
5. Ocorre a remoção de pelo menos um polinário das flores, mas, devido à baixa frutificação natural, as abelhas parecem ser pouco eficientes na deposição do pólen removido.

6. Os folículos demoram cerca de sete meses para abrir e, quando atingem o crescimento máximo, cerca de quatro meses após a polinização, apresentam, em média, $6,44 \mathrm{~cm}$ de comprimento, $2,45 \mathrm{~cm}$ de altura e 3,40 $\mathrm{cm}$ de largura.

7. As condições ideais para avaliar a qualidade de sementes de C. madagascariensis são temperatura de $30^{\circ} \mathrm{C}$ constante, sem suplementação de luz, e contagem de germinação aos sete dias. Sob essas condições, frutos ainda fechados, de coloração verdeamarelada, apresentam sementes com $93 \%$ de germinação.

\section{AGRADECIMENTOS}

Os autores agradecem ao Dr. Fernando A. da Silveira, da Universidade Federal de Minas Gerais, pela identificação das abelhas, e ao $\mathrm{CNPq}$ pelas bolsas de Pesquisa e de Iniciação Científica concedidas, respectivamente, ao primeiro e segundo autores.

\section{REFERÊNCIAS}

BARROSO, G.M.; MORIM, M.P.; PEIXOTO, A.L.; ICHASO, C.L.F. Frutos e sementes: Morfologia aplicada à sistemática de dicotiledôneas. Viçosa: Editora da UFV, 1999. 443p.

BEBAWI, F.F.; McKENZIE, J.R. Pod classification and its role in rubber vine (Cryptostegia grandiflora) germination and emergence. Plant Protection Quarterly, Frankston, v.14, p.3034, 1999. 
CARR, S.G.M.; CARR, D.J. The functional significance of syncarpy. Phytomorphology, Jodhpur, v.11, p.249-256, 1961.

ENDRESS, M.E.; BRUYNS, P.V. A revised classification of the Apocynaceae s.l. The Botanical Review, New York, v.66, p.156, 2000.

FISHBEIN, M.; VENABLE, D.L. Diversity and temporal change in the effective pollinators of Asclepias tuberosa. Ecology, Tempe, v.77, p.1061-1073, 1996.

GRICE, A.C. Seed production, dispersal and germination in Cryptostegia grandiflora and Ziziphus mauritiana, two invasive shrubs in tropical woodlands of northern Australia. Australian Journal of Ecology, Carlton, v.21, p.324-331, 1996.

KEARNS, C.A.; INOUYE, D.W. Techniques for pollination biologists. Colorado: University Press, 1993. 583p.

KLACKENBERG, J. Revision of the genus Cryptostegia R. Br. (Apocynaceae, Periplocoideae). Adansonia, Paris, v.23, p.205218, 2001.

KUNZE, H. Structure and function in asclepiad pollination. Plant Systematics and Evolution, Vienna, v.176, p.227-253, 1991.

LIEDE, S.; KUNZE, H. A descriptive system for corona analysis in Asclepiadaceae and Periplocaceae. Plant Systematics and Evolution, Vienna, v.185, p.275-284, 1993.

LOPES, A.V.; MACHADO, I.C. Pollination and reproductive biology of Rauvolfia grandiflora (Apocynaceae); secondary pollen presentation, herkogamy and self-incompatibility. Plant Biology, New York, v.1, p.547-553, 1999.

LORENZI, H.; SOUZA, H.M. Plantas ornamentais no Brasil. Nova Odessa: Instituto Plantarum, 1999. 1120p.

MAROHASY, J.; FORSTER, P.I. A taxonomic revision of Cryptostegia R. Br. (Asclepiadaceae: Periplocoideae). Australian Systematic Botany, Collingwood, v.4, p.571-577, 1991.

MARTIN, F.W. Staining and observing pollen tubes in the style by means of fluorescence. Stain Technology, Baltimore, v.34, p.125-128, 1959.
OLLERTON, J.; LIEDE, S. Pollination systems in the Asclepiadaceae: a survey and preliminary analysis. Biological Journal of the Linnean Society, London, v.62, p.593-610, 1997.

PIJL, van der L. Principles of dispersal in higher plants. New York: Springer-Verlag. 1982. 214p.

RICHARDS, A.J. Plant breeding systems. London: George Allen \& Unwin, 1986. 529p.

TOMLEY, A.J. The biology of Australian weeds. 26. Cryptostegia grandiflora R. Br. Plant Protection Quarterly, Frankston, v.10, p.122-130, 1995.

VERHOEVEN, R.L.; VENTER, H.J.T. Pollinium structure in Periplocoideae (Apocynaceae). Grana, Oslo, v.37, p.1-14, 1998.

VIEIRA, M.F.; GRABALOS, R. Sistema reprodutivo de Oxypetalum mexiae Malme (Asclepiadaceae), espécie endêmica de Viçosa, MG, Brasil, em perigo de extinção. Acta Botanica Brasilica, São Paulo, v.17, p.137-145, 2003.

VIEIRA, M.F.; SHEPHERD, G.J. Sistema reprodutivo de Oxypetalum appendiculatum Mart. e Oxypetalum banksii Roem. \& Schult. subsp. banksii (Asclepiadaceae). Acta Botanica Brasilica, São Paulo, v.13, p.237-241, 1999.

VIEIRA, M.F.; SHEPHERD, G.J. Removal and insertion of pollinia in flowers of Oxypetalum (Asclepiadaceae) in southeastern Brazil. Revista de Biología Tropical, San José, v.50, p.37-43, 2002.

WALKER, D.B. Postgenital carpel fusion in Catharanthus roseus (Apocynaceae). IV. Significance of the fusion. American Journal of Botany, Columbus, v.65, p.119-121, 1978.

WYATT, R.; BROYLES, S.B. Ecology and evolution of reproduction in milkweeds. Annual Review of Ecology and Systematics, Palo Alto, v.25, p.423-441, 1994.

YEO, P. F. Secundary pollen presentation: form, function and evolution. New York: Springer-Verlag, 1994. 268p. 